\title{
Epidemiologic patterns of leprosy in Vallegrande, Bolivia
}

\author{
A DE MUYNCK* \\ Institute voor Tropische Geneeskunde, 155 Nationale Straat, \\ B 2000 Antwerpen, Belgium
}

Received for publication 3 August 1982

\begin{abstract}
Summary The Andean province of Vallegrande $\left(6,412 \mathrm{~km}^{2} ; 33,532\right.$ inhabitants, of which $99 \%$ are mestizos of Indian-Caucasian descent) has been an endemic area of leprosy for centuries. In 1977 the National Center for Tropical Diseases-CENETROP integrated the existing leprosy control activities in a comprehensive basic health service. The clinical status of all known cases was assessed, and an important effort at case finding was carried out by the basic health teams and the mobile leprosy control team. The overall prevalence rate on 31 July 1980 was 9.4 per thousand. The leprosy problem was mainly one of adults, the prevalence rate in males being $60 \%$ higher than in females. The proportion of lepromatous and borderline forms was $47 \%$. The epidemiological patterns of leprosy in Vallegrande Province are consistent with those generally found in Latin America.
\end{abstract}

\section{Introduction}

Leprosy is endemic in Bolivia, a landlocked country $\left(1,098,000 \mathrm{~km}^{2}, 5,570,105\right.$ inhabitants according to the 1976 census) situated in the heart of South America. The overall estimated prevalence rate is rather low: around one per thousand. In 1976 there were 1705 registered cases but 5,629 estimated ${ }^{1}{ }^{\text {in }}$ 19771832 registered but 3907 estimated cases. $^{2}$ These differences probably do not reflect changes in endemicity, but accentuate the level of uncertainty in assessing the endemicity. The cases are mainly concentrated in three areas: Chuquisaca Department, Beni Department and Vallegrande Province, Santa Cruz Department (Fig. 1).

* Manager, with Dr B Ribera, of the Medical Team of Vallegrande, CENETROP, which consisted of Drs A Talamas, J Encinas, J Salcedo, F Balderrama, E Valdez, F Zenner, N Siles and P-Y Lambert 


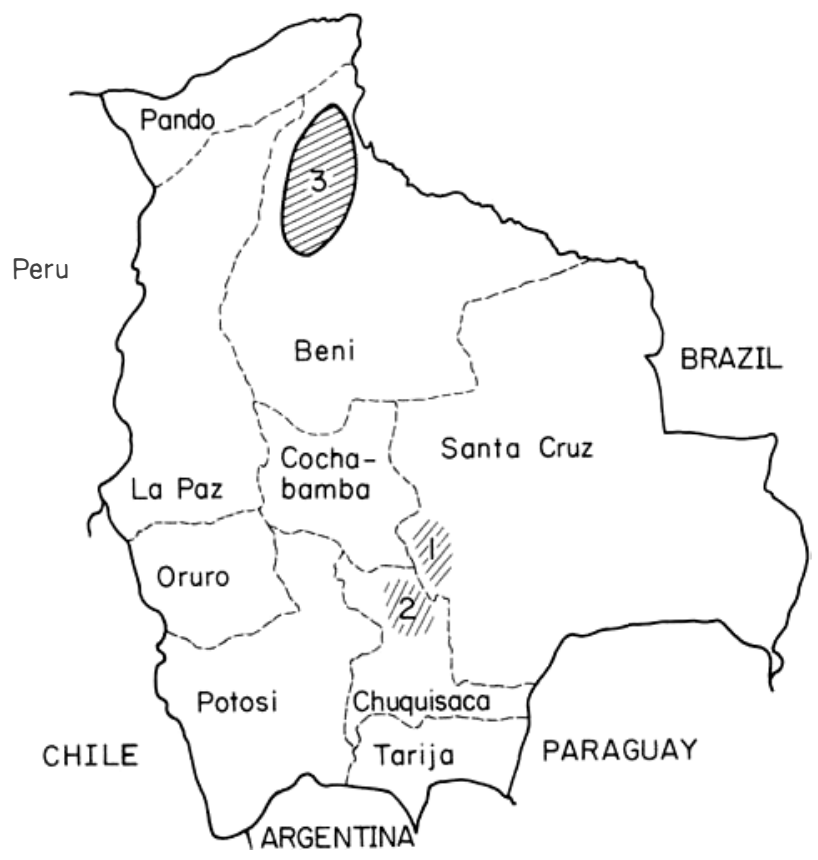

Figure 1. Administrative divisions and leprosy foci, Bolivia. 1, Santa Cruz Department, Vallegrande Province. 2, Chuquisaca Department. 3, Beni Department.

Vallegrande Province $\left(6,414 \mathrm{~km}^{2}, 33,532\right.$ inhabitants*) is a dry Andean valley; its altitude ranges from 460 to $2,989 \mathrm{~m}$ above sea level, with the main plateau at $2,000 \mathrm{~m}$. Ninety-nine percent of the population is mestizo of triple origin: Caucasian, highland Indian, and Guarani Indian. There are no blacks in this valley, although the name of the former leprosarium 'Los Negros' refers to black slaves who lived in this area during the colonial epoch.

The leprosy problem in Vallegrande dates back to the times of the Spanish colonization. A leprosarium was created in colonial times in San Juan del Rosario, $130 \mathrm{~km}$ from Vallegrande City, capital of the province. ${ }^{3}$ The first clinical description of leprosy in this area dates from $1928 .{ }^{4}$ In 1942 the National Leprosy Service was created and the first survey carried out in the province. In 1951 a leprosarium was constructed in Los Negros, situated $70 \mathrm{~km}$ from Vallegrande City. This centre was relocated at the beginning of the 1970's in Jorochito, a locality situated $200 \mathrm{~km}$ from Vallegrande City (Fig. 2).

From 1972 to 1975 a programme of active case finding by means of a complete population survey was carried out in the province: 264 old cases

* Estimates are for 1980 and based on the data from the national census of 1976 and on the natural growth of the population. 


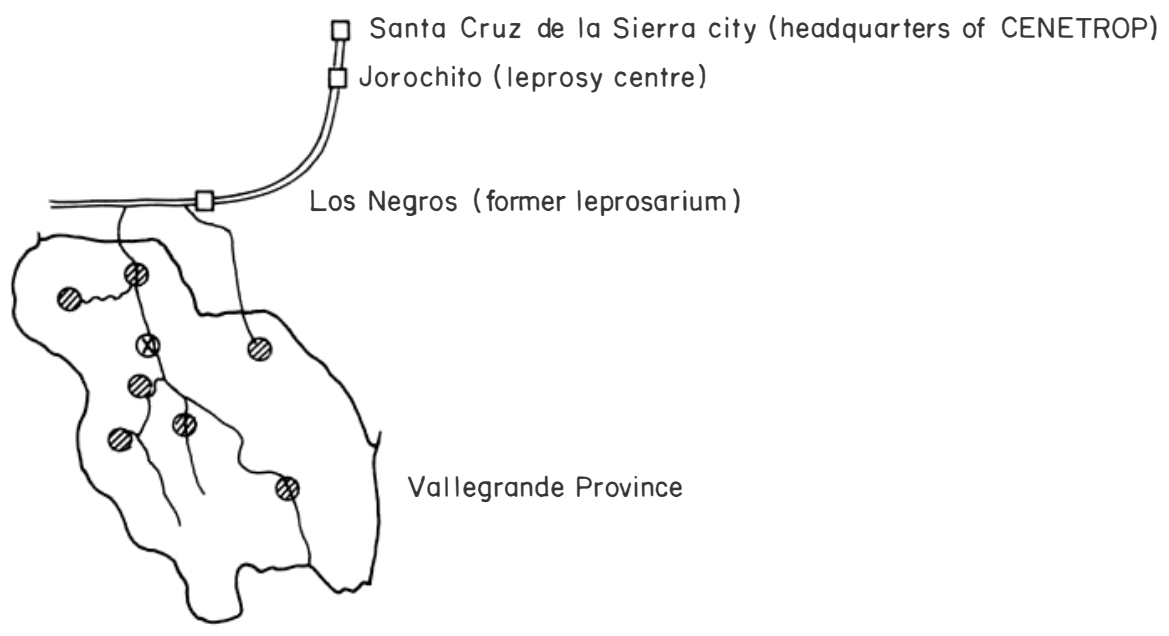

Figure 2. The field and supervising centres, Vallegrande Province. $₫$, areas covered by basic health services. $x$, Vallegrande City. = interdepartmental road Cochabamba-Santa Cruz.

were rediscovered and 190 new cases diagnosed.5,6 A control programme was started, but its efficacy and intensity diminished substantially once the project leader left the area.

In 1977, CENETROP (Centro Nacional de Enfermedades Tropicales) a Belgian-Bolivian project administered jointly by the Ministry of Health from Bolivia and the Tropical Institute from Antwerp, and situated in Santa Cruz de la Sierra, $250 \mathrm{~km}$ from Vallegrande, started a comprehensive basic health service in this province. ${ }^{7}$ The existing leprosy programme was revitalized and 'horizontalized'. ${ }^{8}$ The first task consisted of the assessment of all known cases, and examination of their contacts. Secondly, the control activities, including case finding, were integrated into the primary health care system, and a mobile team was created to cope with the problem of inaccessibility of $52 \%$ of the population. This paper refers to the endemicity and the epidemiologic patterns of leprosy, 31 July 1980.

\section{Materials and Methods}

Following the establishment of the integrated health service, the province, for operational reasons, was divided into two zones: Zone A includes the $48 \%$ of the population who live no more than one hour's travelling time from a local health centre. In this zone, all the known cases and their contacts have been examined by the leprologist of the Ministry of Health, who works in complete co-ordination with CENETROP. All medical histories and classifications have been checked. Active case finding was carried out in some high risk groups (e.g. all direct family and household contacts, schoolchildren). 
All new patients in the OPD of the hospital and in the health centres were routinely screened for leprosy. Zone B includes the remaining 52\% of the population living in areas with limited access to curative health care. They were visited twice a year by a team consisting of a physician and a leprosy technician; all registered cases were visited at home, all histories checked, and 'problem cases' (those with an apparent diagnostic, therapeutic or classification problem) referred to the leprologist. During the visits to these remote areas, general consultations were held, simultaneously serving to screen for leprosy. Some cases continued to go for treatment at Jorochito, and even some new cases were detected there. Their registration was checked in order to have a complete centralized record.

With reference to the old cases a critical assessment of the diagnosis was made through the study of their record, the history of the evolution of the lesions and a biopsy if there were still signs of lesion activity. About $90 \%$ of the old cases were assessed as still needing treatment.

The diagnostic criteria of new cases were: typical skin lesions, clinical signs of neural involvement (thickening of nerves, loss of sensitivity), a positive smear and a conclusive skin biopsy. The diagnosis was made when two of these criteria were present.

The patients were classified following the Madrid scheme by the leprologist; the classification criteria were mainly clinical, smears and biopsies were done when necessary.

The population data are estimates based on the national census of September 1976, and the population dynamics due to natality, mortality, and migrations.

Statistical procedures: The 95\% confidence intervals around the rate ratios were calculated by the 'test based' method, ${ }^{9}$ using a computer program. ${ }^{10}$ In order to examine differences in prevalence between Zone A and B, while controlling for age and gender as variables, a log linear analysis has been carried out by means of a 'LOGLIN' computer package, available at the Harvard School of Public Health, Boston. ${ }^{11}$

\section{Results}

OVERALL PREVALENCE RATE

On 31 July 1980, 316 cases were registered, resulting in an overall prevalence rate of 9.4 per thousand.

\section{AGE AND SEX PATTERN}

Ninety-six percent of the cases were adults (Table 1), the rate ratio for those older than 15 years versus the children being 18.3. There was no difference 
Table 1. Distribution of leprosy cases by age and gender

\begin{tabular}{cccc}
\hline Age (years) & Male & Female & Total \\
\hline $0-14$ & $7(1.0)$ & $7(1.0)$ & $14(1.0)$ \\
$15+$ & $187(19.3)$ & $115(11.6)$ & $302(15.4)$ \\
Total & $194(11.6)$ & $122(7.3)$ & $316(9.4)$ \\
\hline
\end{tabular}

( ) = prevalence rate per thousand population as of 31 July 1980 .

Table 2. Distribution of leprosy cases by clinical form, gender and age in Vallegrande province 1980, compared with the endemicity of 1975

\begin{tabular}{|c|c|c|c|c|c|c|c|}
\hline \multirow[b]{2}{*}{ Clinical form } & \multirow[b]{2}{*}{ Age (years) } & \multicolumn{3}{|c|}{ Vallegrande, 1980} & \multicolumn{3}{|c|}{ Vallegrande, ${ }^{*} 1975$} \\
\hline & & Male & Female & Total & Male & Female & Total \\
\hline \multirow[t]{2}{*}{ Lepromatous } & $0-14$ & 0 & 0 & 0 & 0 & 1 & 1 \\
\hline & $15+$ & 64 & 44 & 108 & 83 & 46 & 129 \\
\hline \multirow[t]{2}{*}{ Tuberculoid } & $0-14$ & 2 & 2 & 4 & 3 & 4 & 7 \\
\hline & $15+$ & 58 & 31 & 89 & 58 & 37 & 95 \\
\hline \multirow[t]{2}{*}{ Indeterminate } & $0-14$ & 5 & 5 & 10 & 7 & 4 & 11 \\
\hline & $15+$ & 42 & 23 & 65 & 43 & 34 & 77 \\
\hline \multirow[t]{2}{*}{ Borderline } & $0-14$ & 0 & 0 & 0 & 1 & 0 & 1 \\
\hline & $15+$ & 23 & 17 & 40 & 22 & 19 & 41 \\
\hline Total & all ages & 194 & 122 & 316 & 217 & 145 & 362 \\
\hline
\end{tabular}

in prevalence amongst girls and boys, while the adult male rates were $60 \%$ higher than the adult female ones.

\section{CLINICAL PATTERN}

Thirty-four percent of the cases were lepromatous, 13\% borderline, 29\% tuberculoid and $24 \%$ indeterminate (Table 2). The multibacillary (lepromatous and borderline) cases were limited to adults, and the rate ratio of males versus females showed a consistent male predominance in nearly all clinical types (Table 3).

\section{HETEROGENEITY OF THE PREVALENCE AT THE LEVEL OF VILLAGES} AND ZONES

There were marked differences in the prevalence among the villages, the highest endemicity figures were observed in La Higuera (65.5 per thousand) and El Peñon (36.1 per thousand).

Ninety-eight cases were living in Zone A (prevalence rate 6.1 per thousand) and 218 in Zone B (prevalence rate 12.5 per thousand). The difference between 
Table 3. Prevalence rates* of the different clinical forms in the adult male and female population, the rate ratio (male rates versus female ones) and the $95 \%$ confidence intervals around the rate ratios

\begin{tabular}{lccccc}
\hline \multicolumn{1}{c}{ P.R. } & Lepromatous & Tuberculoid & Indeterminate & Borderline & Total \\
\hline Male & 6.6 & 6.0 & 4.3 & 2.4 & 19.3 \\
Female & 4.4 & 3.1 & 2.3 & 1.7 & 11.6 \\
Both sexes & 5.5 & 4.5 & 3.3 & 2.0 & 15.4 \\
Rate ratio & 1.5 & 1.9 & 1.9 & 1.3 & 1.7 \\
95\% c.i. (1) & 1.02 & 1.25 & 1.14 & 0.79 & 1.34 \\
$95 \%$ c.i. (u) & 2.21 & 2.90 & 3.17 & 2.15 & 2.15 \\
\hline
\end{tabular}

1: lower bound of the $95 \%$ confidence interval.

u: upper bound of the $95 \%$ confidence interval.

*: prevalence rate per thousand (P.R.).

the rates in these two zones is highly significant $\left(\chi_{(1 \mathrm{df})}^{2}=37, p \ll 0.001\right)$. The problem of the rate difference, while controlling for age and sex, has been examined by fitting a loglinear model to the lepromatous data. The most parsimonious model that fits the data is the one with the following interaction terms: zone $*$ lepromatous prevalence; gender $*$ lepromatous prevalence; age * lepromatous prevalence. The $\mathrm{G}^{2}$ with $5 \mathrm{df}$ (degrees of freedom) was 10.61 , resulting in a $p$-value of 0.060 . The contribution of the zone parameter was highly significant: the conditional $\mathrm{G}^{2}(1 \mathrm{df})$ was 18.6 , with a $p$-value of $<0.001$.

\section{Discussion}

Leprosy is practically hyperendemic in Vallegrande, with the overall prevalence rate remaining nearly constant since the survey of $1972-1975 . .^{5}$ Given that for the determination of the 1980 rates all cases were considered, regardless of the activity of the lesions and the duration of the treatment, an increase was expected. Two reasons might explain the lack of an increase of the endemicity. The first is emigration, which is a serious problem in Vallegrande, and results in a slightly negative growth rate for the population. Emigration seems to be non-selective as regards leprosy in general or clinical forms in particular. A second reason could be an under reporting of new cases. Although the principle of 'horizontalization' was introduced as a panacea for the case detection and case-holding deficiencies of the existing vertical programme, it seems evident now that case detection has not come up to expectations, despite a reasonable effort by all team members. The magnitude of the under reporting is unknown, although we estimate it to be small.

The leprosy problem in Vallegrande was very small among the children 
and not even found in the under-fives. There was no difference in the prevalence rates between boys and girls. This is a common Latin American pattern, ${ }^{12}$ other examples of which were reported in $\mathrm{Cuba}^{13}$ and Argentina. ${ }^{14}$ In order to determine whether there was under reporting of cases in children, a school survey was carried out. Of the 3,524 children examined by our leprologist, no single new case was detected although 1 case, previously treated but subsequently lost to follow-up, was observed.

In Latin America, the multibacillary forms are prominent, and are more common in the adult male group. ${ }^{15}$ The sex index for the lepromatous forms is estimated ${ }^{12}$ as 200 ; in Vallegrande our figure was 145 . The overall proportion of the multibacillary forms was $47 \%$, a percentage identical to the other one observed $;^{12}$ similar percentages are reported in Brazil $(51 \%)^{16}$ and Argentina (56\%). ${ }^{17}$ This seems to be the order of magnitude generally found in Latin America. ${ }^{1,18}$

In Vallegrande the distribution of the leprosy endemicity is not homogeneous. But could biases explain the rate differences between zones A and B? Selection bias: if any, should presumably produce an under reporting in the inaccessible area (zone B), thus fortifying the observed association between area and prevalence rate. Observation bias: although the whole team was under the supervision of one and the same leprologist, who herself examined all cases of zone $\mathrm{A}$ and checked at least all the records of the patients of zone $\mathrm{B}$, observation bias is possible. Under the assumption that the assessment of the lepromatous cases is less prone to observer subjectivity, the log linear analysis was limited to this group. The difference between zone A and B remained highly significant, consequently serious observation bias is unlikely. Confounding biases: the association between area and prevalence rate is quite strong; it seems therefore unlikely that the observed association could be explained by uncontrolled variables.

The proximity to a health centre (characteristic of zone A) is thus only a 'proxy' for factors that determine the prevalence. Given that the difference in endemicity between zones A and B was the result of the analysis and not the confirmation of a prior hypothesis, a new study is indicated to confirm this difference and to investigate the association between the disease and causal factors like crowding, level of hygiene, skin contact, nutritional status, genetic factors, temperature, poverty, humidity, exposure to tuberculosis. ${ }^{19-21}$ Recently epidemiologists have observed that the case-control methods, largely and successfully applied to chronic diseases, deserve to be used in causal research in leprosy. ${ }^{21,24}$ Therefore this new study should compare the prevalent cases of the moderate (zone A) and high endemic area (zone B) regarding their exposure to those potential causal factors, by case-control techniques. The control of variables and the study of risk factors and of interactions should be carried out by multivariate statistical modelling.

Prevalence rates and patterns are important tools for the description of a 
leprosy problem, but for the analysis of the evolution of endemicity in a given community, incidence data are preferable, ${ }^{22}$ (Meade, 1971). The latter type of data has been noted to be sparse in the different endemic areas. ${ }^{23} \mathrm{We}$ had hoped that our project would produce incidence data. Our field team found it impossible however to continually update the vital statistics of births, deaths and migrations, without diverting time and effort from the main task.

\section{Acknowledgments}

Financial support was given by The Bolivian Ministry of Health, The Tropical Institute of Antwerp, and the Damianfounds from Belgium.

\section{References}

1 Motta CP. Leprosy in the Americas region (AMRO). Lepr Rev, 1980; 51: 285-94.

2 Panamerican Health Organization. Weekly Epidemic Report, 1978; 53(20): 147.

3 Suarez QJ. Estado actual del problema de la lepra en Bolivia. Gaceta Medica Boliviana, 1949; 20: 45 .

${ }^{4}$ Suarez Arroyo A. Influencia de la lepra en el sentido de la vista. Revista del Instituto Medico Sucre, 1928; 49: 36-43

5 Girardin F. Censo demografico en la provincia de Vallegrande, departamento de Santa Cruz, Bolivia, 1972-1975. Boletin informativo del CENETROP, 1976; 2(8): 24-36.

${ }^{6}$ Girardin F. La Campaña Antiliprosa en Vallegrande. Boletin informativo del CENETROP, 1978; 4: 140-51.

7 De Muynck A. CENETROP: A joint Belgian-Bolivian medical development project in Santa Cruz, Bolivia. Annales de la Société belge de Médecine Tropicale, 1979; 59: $325-7$.

${ }^{8}$ De Muynck A., Ribera B, Balderrama F, Salcedo J. Integrated rural basic health care in Vallegrande, Bolivia. Annales de la Société belge de Médecine Tropicale, 1979; 59 (suppl): 33-45.

9 Miettinen OS. Estimability and estimation in case-referent studies. Amer J Epid, 1976; 103: $226-35$.

10 Rothman K, Boice J. Epidemiologic Analysis with a Programmable Calculator. NIH publication No 79-1649 1979.

11 Bishop Y, Fienberg S, Holland P. Discrete Multivariate Analysis. Theory and Practice. The MIT Press, Cambridge, Massachusetts 1975.

12 Motta CP. The epidemiological situation in the Americas. Lepr Rev, 1981; 52 (suppl 1): 61-8.

13 Fernandez GB, Fernandez BR. Revisión clinico-patologica de 200 pacientes del hospital 'Antileproso del Rincón'. Revista Cubana de Medicina Tropical, 1974; 26: 57-66.

14 Leprosy Advisory Team-LAT-. Report of a survey in Argentina, April to December 1965. WHO/PA 276.651965.

15 Sansarricq H. Epidemiological patterns of leprosy in different parts of the world. Paper presented at the scientific conference on leprosy, Arusha, Tanzania. 1978.

16 Belda W. Aspectos epidemiologicos da Hanseniose no estada de Sǎo Paulo en 1974. Hansenologia Internationalis, 1976; 1: 11-23. 
17 Consigle CA, Chappuis EJ, Vasquez CA, Achaval CF. Lepra: Importancia del grupo familiar. Leprologia , 1973; 18: 19-25.

18 Brubaker ML. Leprosy in the Americas. Leprologia, 1974; 19: 168-77.

19 Irgens LM. Leprosy in Norway. Lepr Rev, 1980; 51 (suppl): 1-130.

20 Irgens LM. Epidemiological aspects and implications of the disappearance of leprosy from Norway: Some factors contributing to the decline. Lepr Rev, 1981; 52(suppl. 1): 147-66.

21 Fine PEM. Problems in the collection and analysis of data in leprosy studies. Lepr Rev, 1981 ; 52(suppl 1): 197-206.

22 Meade TW. Epidemiology and leprosy control. Lepr Rev, 1971; 42: 14-25.

23 Lechat MF. L'épidemiologie de la lèpre au cours des 100 dernières années. Int J Lepr, 1973; 41: 298-306.

24 Lechat MF. Leprosy at the interface between epidemiology and basic research. Lepr Rev, 1981; 52 (suppl 1): 299-304. 